\title{
Is basaloid squamous carcinoma of the esophagus high-grade malignancy? A report of six cases
}

\author{
Shingo Nakashima ${ }^{1}$, Atsushi Shiozaki ${ }^{1}$, Hitoshi Fujiwara ${ }^{1}$, Daisuke I chikawa ${ }^{1}$, Toshiyuki Kosuga $^{1}$, \\ Hirotaka Konishi $^{1}$, Ryo Morimura ${ }^{1}$, Yasutoshi Murayama ${ }^{1}$, Shuhei Komatsu ${ }^{1}$, Hisashi I koma ${ }^{1}$, \\ Yoshiaki Kuriu ${ }^{1}$, Masayoshi Nakanishi ${ }^{1}$, Kazuma Okamoto ${ }^{1}$, Chouhei Sakakura ${ }^{1}$, Mitsuo \\ Kishimoto ${ }^{2}$, Akio Yanagisawa ${ }^{2}$, Eigo Otsuji ${ }^{1}$ \\ 1. Division of Digestive Surgery, Department of Surgery, Kyoto Prefectural University of Medicine, Kyoto, Japan. \\ 2. Department of Pathology, Kyoto Prefectural University of Medicine, Kyoto, Japan.
}

Correspondence: Atsushi Shiozaki. Address: Division of Digestive Surgery, Department of Surgery, Kyoto Prefectural University of Medicine, Kajii-cho, Kamigyo-ku, Kyoto, Japan. E-mail: shiozaki@koto.kpu-m.ac.jp

Received: November 23, 2014

Accepted: January 14, $2015 \quad$ Online Published: February 3, 2015

DOI : $10.5430 /$ crcp.v2n1p91

URL: http://dx.doi.org/10.5430/crcp.v2n1p91

\begin{abstract}
Basaloid squamous carcinoma of the esophagus (BSCE) is a rare malignant disease. We herein described six cases of BSCE treated by esophagectomy in our department, the clinicopathological features of which were analyzed. Only one of the six cases was diagnosed with BSCE prior to surgery. The depth of tumor invasion was T3 and T1b in 4 and 2 cases, respectively. Metastatic lymph nodes were detected in two cases of advanced carcinoma. All four cases of advanced carcinoma recurred and died of metastasis, and the period of disease-free survival and overall survival after surgery was 5-18 months and 24-42 months, respectively. On the other hand, as of 21 months and 52 months after surgery, two patients with superficial carcinoma have been free from recurrence. Immunohistochemistry revealed that the anti-phosphohistone H3 (PHH3) mitotic index (MI) was significantly higher and the p21 labeling index (LI) was significantly lower than those in conventional esophageal squamous cell carcinoma. Although BSCE immunohistochemically suggests high-grade malignancy, radical excision may contribute to a better outcome in the early stage.
\end{abstract}

\section{Key words}

Basaloid squamous carcinoma, Phosphohistone H3, p21

\section{I ntroduction}

Basaloid squamous carcinoma (BSC) is a distinct variant of squamous cell carcinoma (SCC), which first described as a laryngopharyngeal tumor by Wain et al. in $1986^{[1]}$. Basaloid squamous carcinoma of the esophagus (BSCE) is a rare tumor, accounting for $0.4 \%-3.6 \%$ of all esophageal carcinomas ${ }^{[2]}$. BSCE is generally considered to have a poorer outcome than that of SCC because it is characterized by a poor degree of differentiation, high proliferative activity ${ }^{[3]}$, high biological malignancy ${ }^{[4-6]}$, and high incidence of distant metastasis.

Immunohistochemistry using various molecular biological markers, such as cytokeratin subtypes, p53, B-cell lymphoma 2 (bcl-2), c-myc, cyclin D1 (CCND1), and E-cadherin, have recently been examined in patients with $\mathrm{BSCE}^{[2,6-10]}$; however, no consensus has been reached. 
Histone $\mathrm{H} 3$ is one of the five histone proteins that together form the major protein constituents of chromatin in eukaryotic cells. Histone H3 (Ser10) is phosphorylated in association with mitotic chromatin condensation in the late G2 and M phases of the cell cycle ${ }^{[1]}$. Therefore, anti-phosphohistone H3 (PHH3) can be used as a specific mitotic marker. We previously demonstrated that the expression of PHH3 had an impact on the prognosis of patients with esophageal $\mathrm{SCC}^{[12]}$.

p21 is a cyclin-dependent kinase inhibitor that directly inhibits the activity of the CCND1/CDK4 complex. We previously reported a correlation between a high p21 LI and good prognosis in SCC patients ${ }^{[13]}$.

To the best of our knowledge, the value of PHH3 and p21 expression in BSCE has not been previously evaluated. We herein described six cases of BSCE treated by esophagectomy and analyzed their clinicopathological features and the expression of $\mathrm{p} 21$ and $\mathrm{PHH} 3$.

\section{Case presentation}

\subsection{Materials and methods}

\subsubsection{Patients}

In the present study, BSC was defined as the presence of atypical basaloid cells accounting for more than $50 \%$ of the tumor. Six (among 481 cases of esophageal SCC and adenocarcinoma, 1.2\%) surgical cases were diagnosed pathologically as BSCE between April 1999 and March 2012 at Kyoto Prefectural University of Medicine (Kyoto, Japan).

\subsubsection{I mmunohistochemistry}

Paraffin sections ( $3-\mu \mathrm{m}$ thick) of tumor tissue were subjected to immunohistochemical staining for PHH3 and p21 using the avidin-biotin-peroxidase method. Briefly, paraffin sections were dewaxed in xylene and hydrated through a graded series of alcohols. Antigen retrieval was performed by heating the samples in Dako REAL Target Retrieval Solution (Glostrup, Denmark) for $40 \mathrm{~min}$ at $95^{\circ} \mathrm{C}$. Endogenous peroxidase activity was quenched by incubating the sections for $30 \mathrm{~min}$ in $0.3 \% \mathrm{H}_{2} \mathrm{O}_{2}$. The sections were treated with a protein blocker, and were then incubated for 1 hour at room temperature with the following antibodies: a PHH3 antibody (rabbit polyclonal PHH3 antibody [Ser 10], diluted 1:5,000, from Millipore, Billerica, MA, USA) and p21 antibody (rabbit polyclonal p21 antibody, diluted 1:1,000, from Cell Signaling Technology, Beverly, MA, USA). The avidin-biotin-peroxidase complex system (Vectastain ABC Elite kit, from Vector Laboratories, Burlingame, CA, USA) was used for color development with diaminobenzidine tetrahydrochloride. The sections were counterstained with hematoxylin and were subsequently dehydrated through a graded series of alcohols, cleared in xylene, and mounted. Control sections of known positive SCC were included in each antibody run, and negative control sections were produced by omitting the primary antibody.

The determination of proliferative activity by immunohistochemistry was performed quantitatively by counting immunereactive tumor cells in the most intensely stained areas. The PHH3 mitotic index (MI) was calculated as the number of positive cells in 10 consecutive high-power fields $(400 \times)$ in areas with the highest mitotic activity. Only distinct immunoreactive tumor cell nuclei were counted. p21-stained cells were quantified in 5 selected fields of the highest proliferative activity at $400 \times$ magnification. The LI of each case was calculated as the number of positive cells divided by the total number of examined cells in all examined fields.

\subsubsection{Statistical analysis}

Statistical analyses were carried out using the Student's $t$-test for comparisons between two groups. Differences were considered significant when the associated $p$-value was less than 0.05 . All analyses were performed using statistical software (JMP, version 10; SAS Institute Inc., Cary, NC, USA). 


\subsection{Results}

\subsubsection{Clinicopathological features and postoperative courses}

Table. Clinicopathological features and postoperative courses of six patients with BSCE

\begin{tabular}{|c|c|c|c|c|c|c|}
\hline Case & 1 & 2 & 3 & 4 & 5 & 6 \\
\hline Age/sex & $71 / \mathrm{F}$ & $73 / \mathrm{M}$ & $68 / \mathrm{M}$ & $51 / \mathrm{M}$ & $67 / \mathrm{M}$ & $67 / \mathrm{M}$ \\
\hline Location & MtLt & AeLt & $\mathrm{Lt}$ & Mt & $\mathrm{Mt}$ & Mt \\
\hline $\begin{array}{l}\text { Macroscopic } \\
\text { classification }\end{array}$ & Type3 & Type3 & Type3 & Type2 & II a+ II c & II a+ II c \\
\hline Biopsy specimen & scc & $\mathrm{scc}+\mathrm{bsc}$ & $\operatorname{scc}$ & $\operatorname{scc}$ & $\operatorname{scc}$ & $\operatorname{scc}$ \\
\hline pT & $\mathrm{T} 3$ & $\mathrm{~T} 3$ & T3 & $\mathrm{T} 3$ & $\mathrm{~T} 1 \mathrm{~b}$ & $\mathrm{~T} 1 \mathrm{~b}$ \\
\hline $\mathrm{pN}$ & No & $\mathrm{N} 2$ & N1 & No & No & No \\
\hline ly & - & + & + & - & - & - \\
\hline $\mathrm{v}$ & + & + & + & + & - & + \\
\hline pStage & II & III & III & II & I & I \\
\hline $\begin{array}{l}\text { Preoperative } \\
\text { chemotherapy }\end{array}$ & - & - & UFT+CDDP & - & - & - \\
\hline $\begin{array}{l}\text { Postoperative adjuvant } \\
\text { chemotherapy }\end{array}$ & - & CPT-11+CDGP & - & - & - & - \\
\hline $\begin{array}{l}\text { Chemotherapy after } \\
\text { recurrence }\end{array}$ & $\begin{array}{l}\text { docetaxel, } \\
\text { paclitaxel, } \\
\text { CPT-11 }\end{array}$ & UFT & $\begin{array}{l}\text { cisplatin plus } \\
\text { 5-FU, docetaxel }\end{array}$ & $\begin{array}{l}\text { cisplatin } \\
\text { plus 5-FU }\end{array}$ & - & - \\
\hline PHH3 MI & 25 & 33 & 39 & 55 & 86 & 28 \\
\hline p21 LI & 2.2 & 28.5 & 1.8 & 1.8 & 7.6 & 3.6 \\
\hline DFS (months) & 5 & 18 & 9 & 7 & 52 & 21 \\
\hline OS (months) & 29 & 24 & 42 & 25 & 52 & 21 \\
\hline Outcome & dead & dead & dead & dead & alive & alive \\
\hline
\end{tabular}

Note. The terms and definitions used follow the criteria of the Japanese Classification of Esophageal Cancer, 10th edition; The macroscopic classification used was according to endoscopic classification based on the guidelines for Clinical and Pathological Studies of the Japanese Society for Esophageal Disease; Mt: middle thoracic esophagus; Lt: lower thoracic esophagus; Ae: abdominal esophagus; DFS: disease-free survival; OS: overall survival; PHH3 MI: phosphohistone h3 mitotic index; LI: labeling index

The table shows the clinicopathological features and postoperative courses of the six patients. Their mean age was 66 years old. Five of the six patients were male. Regarding the location of the tumor, middle thoracic, lower thoracic and abdominal esophagus was 4, 1 and 1 cases, respectively. Only one of the six cases was diagnosed with BSC before surgery. Only 1 case of advanced carcinoma received preoperative chemotherapy. All six patients underwent curative subtotal esophagectomy and two-field lymphadenectomy. Microscopically, the major component was basaloid cells. Solid nests with comedo-type central necrosis and the deposition of a basement membrane-like material were identified (see Figure 1). A trabecular structure and cribriform pattern were also found. Regarding the depth of tumor invasion, T3 and T1b was 4 and 2 cases, respectively. Metastatic lymph nodes were detected in 2 cases of advanced carcinoma. The positive rate of vessel invasion was $100 \%(4 / 4)$ in advanced carcinoma and 50\% (1/2) in superficial carcinoma. The positive rate of lymphatic invasion was 50\% (2/4) in advanced carcinoma and $0 \%(0 / 2)$ in superficial carcinoma. One case of metastatic lymph nodes received postoperative adjuvant chemotherapy (CPT-11 plus CDGP). All four advanced carcinoma recurred and died of metastasis. Chemotherapy (cisplatin plus 5-FU [FP], docetaxel, paclitaxel, and CPT-11) after recurrence was not effective in any case. The median period from surgery to recurrence was 8 months (5-18 months). Initial metastatic lesions were detected in the lung ( 2 case), liver (1 case), and para-aortic lymph nodes ( 1 case). Overall survival after surgery in patients with advanced carcinoma was 24-42 months. On the other hand, as of 21 months and 52 months after surgery, two patients with superficial carcinoma have been free from recurrence. 

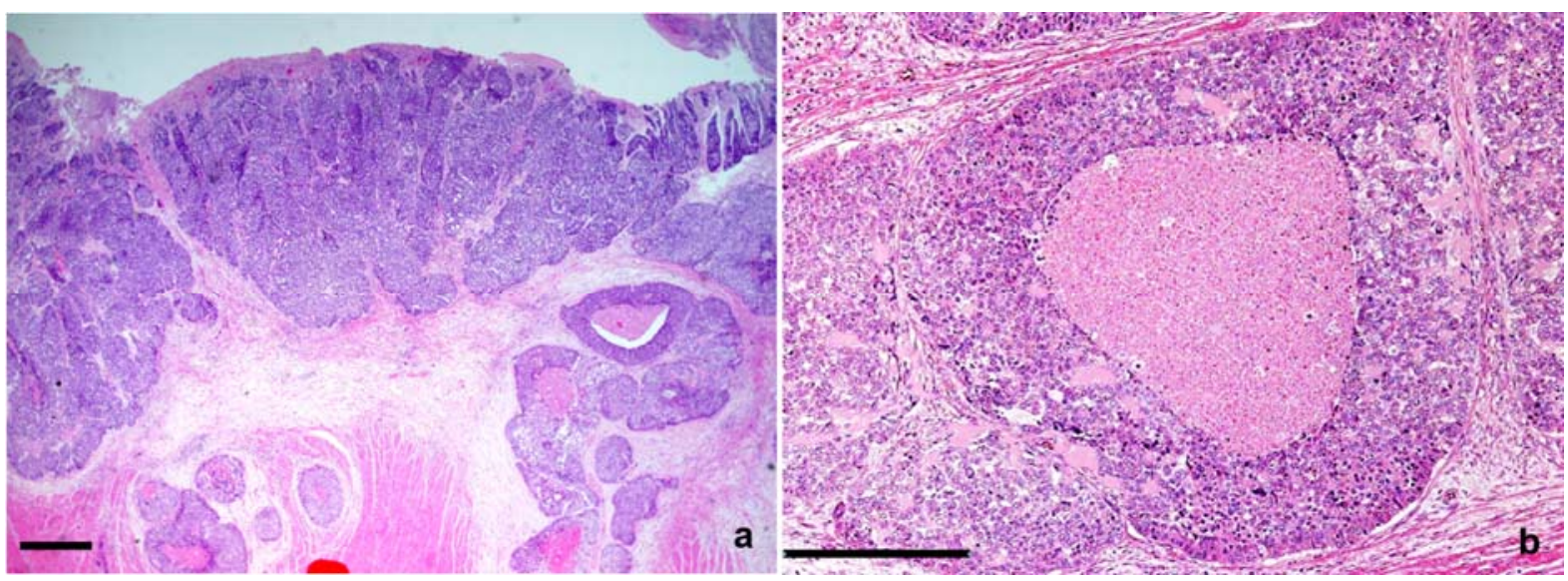

Figure 1. Microscopic examination of the excised tumor of case 1. (a) The tumor was composed of basaloid cells arranged in solid nests (HE staining; 20×, Bar $=500 \mu \mathrm{m}$ ). (b) Central necrosis (comedo-type necrosis) and deposition of a basement membrane-like material were observed (HE staining; $100 \times$, Bar $=500 \mu \mathrm{m}$ ).

\subsubsection{I mmunohistochemistry}

Figure 2 and 3 show the immunohistochemistry results of PHH3 and p21.
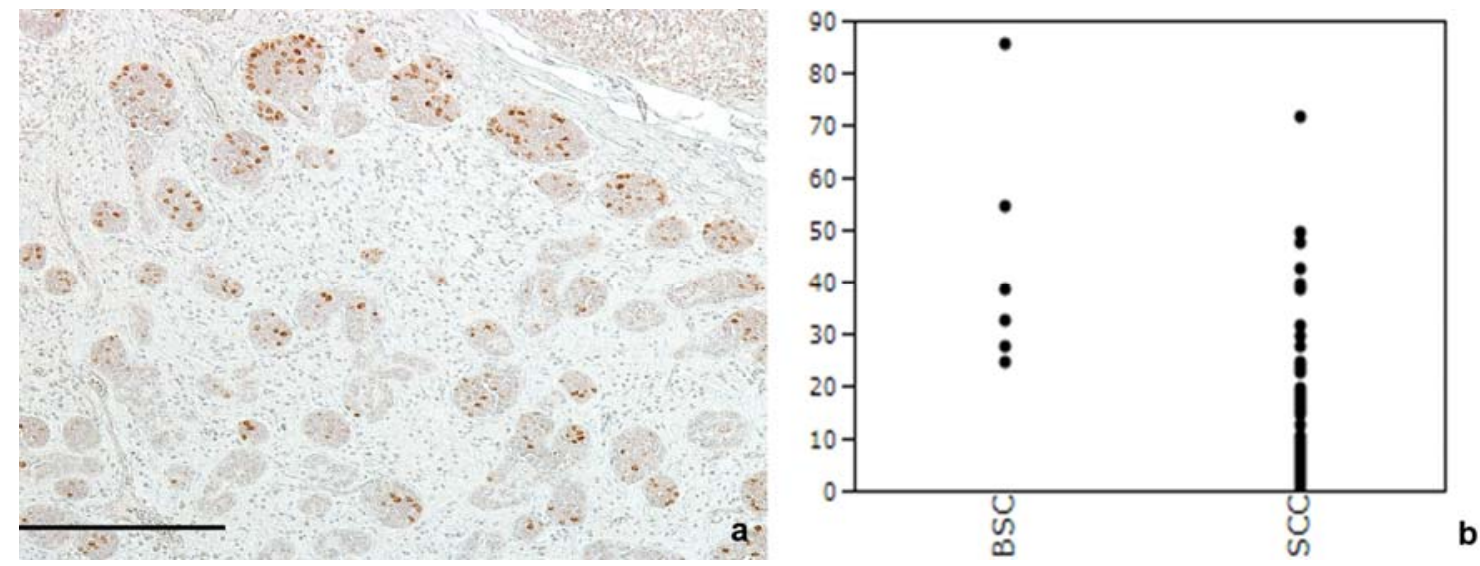

Figure 2. PHH3 mitotic index. (a) Immunohistochemical staining of a BSCE tumor sample with PHH3 antibodies (100×, Bar $=500 \mu \mathrm{m}$ ). (b) PHH3 MIs between BSCE samples and SCC samples ${ }^{[12]}$. Statistical analysis: Student's t-test. $p<.001$.


Figure 3. p21 labeling index. (a) Immunohistochemical staining of a BSCE tumor sample with p21 antibodies (100×, Bar $=500 \mu \mathrm{m})$. (b) p21 LIs between BSCE samples and SCC samples ${ }^{[13]}$. Statistical analysis: Student's $t$-test. 


\section{Discussion}

BSC is an uncommon malignant epithelial neoplasm, which consists of small cells that resemble basal cells, that forms nests of various sizes or trabecular arrangement, and occasionally forms irregular adenoid or small cystic structures. BSC is also characterized by the deposition of basement membrane-like substances both within and outside tumor nests ${ }^{[2,14]}$. BSCE has predominantly been observed in the middle thoracic esophagus in men ${ }^{[2,3,5]}$. In our series, five of six patients were male and tumors were mostly located in the middle part of the thoracic esophagus.

The growth pattern of BSCE is downward and expansive even at an early stage ${ }^{[15]}$. Superficial BSCE shows a submucosal tumor-like form or polypoid elevation ${ }^{[16,17]}$. Even in advanced BSCE, tumors are frequently covered by a normal epithelium ${ }^{[9,16]}$. Therefore, only $10 \%$ of BSCE cases are correctly diagnosed because of the difficulties associated with diagnosing BSCE by preoperative biopsy ${ }^{[16]}$. In our series, only one of six patients was diagnosed with BSCE before surgery. BSCE presents with high venous invasion because it primarily progresses in the stratum submucosa. Ishii et al. reported that the rates of venous invasion in patients who had superficial BSCE and BSCE with T2 or deeper invasion were $38 \%$ and $85 \%$. The rate of venous invasion of BSCE was higher than the mean rate of superficial SCC (22.7\%); however, no significant differences were observed for lymphatic invasion ${ }^{[16]}$. BSCE frequently progresses via hematogenous metastases rather than lymph node metastases ${ }^{[8,17,18]}$. In our series, the positive rate of vessel invasion was $100 \%(4 / 4)$ in advanced carcinoma and 50\% (1/2) in superficial carcinoma. Hematogenous metastasis to organs such as the lung and liver occurred in three cases of advanced carcinoma.

In patients with SCC, we reported that a low PHH3 MI (cut-off value of 10) was correlated with good prognosis ${ }^{[12]}$, while a high p21 LI (cut-off value of 30\%) was also correlated with good prognosis ${ }^{[13]}$. In this study, the PHH3 MIs of BSCE were significantly higher than those of conventional SCC, and those of all BSCE cases were more than 10. Furthermore, the p21 LIs of BSCE was significantly lower than those of conventional SCC, and those of all BSCE cases were less than $30 \%$. In this study, we demonstrated that BSCE exhibited high proliferative activity and high-grade malignancy.

No standard treatment has been established for BSCE. Combination chemotherapy with 5FU plus CDDP (FP) was


temporarily suppressed tumor progression of BSCE ${ }^{[10]}$, but there was no report that it was effective for BSCE. In our series, postoperative adjuvant chemotherapy was performed in one of four advanced carcinoma cases. The patient who received postoperative adjuvant chemotherapy has been free from tumor recurrence for 18 months following surgery; however, tumor recurrence occurred within 5-9 months after surgery in the three cases that did not receive postoperative adjuvant chemotherapy. Therefore, postoperative chemotherapy may inhibit the recurrence of malignancy. Meanwhile, chemotherapy such as FP, taxan, and CPT-11 was not effective after tumor recurrence in our cases. The further accumulation of cases is necessary to establish effective and concrete protocols for such treatments.

BSCE generally has a poor outcome; however, a recent study has suggested that outcomes after curative resection may not differ significantly from those of common SCC ${ }^{[3,8,16,19]}$. In a comparison of 60 cases of BSCE with typical SCC, Yoshioka et al. reported that the survival rates with early stage BSCE were similar to those of patients with common SCC. However, no long-term survivors were found among patients with advanced stage BSCE ${ }^{[20]}$. In our study, all four cases of advanced carcinoma recurred and died of metastasis. On the other hand, two patients with superficial carcinoma have been free from recurrence as of 21 months and 52 months after surgery. BSCE immunohistochemically suggests high-grade malignancy and has a poor outcome in the advanced stage of the disease; radical excision may contribute to a better outcome in the early stage.

\section{Competing interests}

The authors declare that they have no competing interests. 


\section{References}

[1] Wain SL, Kier R, Vollmer RT, Bossen EH. Basaloid-squamous carcinoma of the tongue, hypopharynx, and larynx: report of 10 cases. Hum Pathol. 1986; 17: 1158-66. http://dx.doi.org/10.1016/S0046-8177(86)80422-1

[2] Arai T, Aida J, Nakamura K, Ushida Y, Takubo K. Clinicopathologic characteristics of basaloid squamous carcinoma of the esophagus. Esophagus. 2011; 8: 169-77. http://dx.doi.org/10.1007/s10388-011-0280-x

[3] Serbia M, Verreet P, Bittinger F, et al. Basaloid squamous cell carcinoma of the esophagus: diagnosis and prognosis. Cancer. 1997; 79: 1871-8. http://dx.doi.org/10.1002/(SICI)1097-0142(19970515)79:10<1871::AID-CNCR5>3.0.CO;2-J

[4] Takubo K, Mafune K, Tanaka Y, Miyama T, Fujita K. Basaloid-squamous carcinoma of the esophagus with marked deposition of basement membrane substance. Acta pathol Jpn. 1991; 41: 59-64. PMid: 2031457.

[5] Ide F, Shimoyama T, Haga H, Horie N. Basaloid squamous cell carcinoma of the esophagus metastatic to the gingiva: a case report. Oral Surg Oral Med Oral Pathol Oral Radiol Endod. 1997; 83: 584-7. http://dx.doi.org/10.1016/S1079-2104(97)90124-4

[6] Koide N, Koike S, Adachi W, Amano J, Usuda N, Nagata T. Immunohistochemical expression of bcl-2 protein in squamous cell carcinoma and basaloid carcinoma of the esophagus. Surg Today. 1997; 27: 685-91. PMid: 9306579. http://dx.doi.org/10.1007/BF02384977

[7] Imamhasan A, Mitomi H, Saito T, Hayashi T, Takahashi M, Kajiyama Y, et al. Immunohistochemical and oncogenetic analyses of the esophageal basaloid squamous cell carcinoma in comparison with conventional squamous cell carcinomas. Hum Pathol. 2012; 43: 2012-23. PMid: 22607702. http://dx.doi.org/10.1016/j.humpath.2012.02.010

[8] Saito S, Hosoya Y, Zuiki T, Hyodo M, Lefor A, Sata N, et al. A clinicopathological study of basaloid squamous carcinoma of the esophagus. Esophagus. 2009; 6: 177-81. http://dx.doi.org/10.1007/s10388-009-0202-3

[9] Ohashi K, Horiguchi S, Moriyama S, Hishima T, Hayashi Y, Momma K, et al. Superficial basaloid squamous carcinoma of the esophagus. A clinicopathological and immunohistochemical study of 12 cases. Pathol Res Pract. 2003; 16: 342-35.

[10] Shibata Y, Baba E, Ariyama H, Miki R, Ogami N, Arita S, et al. Metastatic basaloid-squamous cell carcinoma of the esophagus treated by 5-fluorouracil and cisplatin. World J Gastroenterol. 2007; 13: 3634-7. PMid: 17659717. http://dx.doi.org/10.3748/wjg.v13.i26.3634

[11] Hendzel MJ, Wei Y, Mancini MA, Van Hooser A, Ranalli T, Brinkley BR, et al. Mitosis-specific phosphorylation of histone H3 initiates primarily within pericentromeric heterochromatin during G2 and spreads in an ordered fashion coincident with mitotic chromosome condensation. Chromosoma 1997; 106: 348-60. PMid: 9362543. http://dx.doi.org/10.1007/s004120050256

[12] Nakashima S, Shiozaki A, Ichikawa D, Komatsu S, Konishi H, Iitaka D, et al. Anti-Phosphohistone H3 as an independent prognostic factor in human esophageal squamous cell carcinoma. Anticancer Res. 2013; 33: 461-7. PMid: 23393337.

[13] Shiozaki A, Nakashima S, Ichikawa D, Fujiwara H, Konishi H, Komatsu S, et al. Prognostic Significance of p21 Expression in Patients with Esophageal Squamous Cell Carcinoma. Anticancer Res. 2013; 33: 4329-35. PMid: 24123000.

[14] Wain SL, Kier R, Vollmer RT, Bossen EH. Basaloid-squamous carcinoma of the tongue, hypopharynx, and larynx: report of 10 cases. Hum Pathol. 1986; 17: 1158-66. http://dx.doi.org/10.1016/S0046-8177(86)80422-1

[15] Kato T, Morita T, Fujita M, et al. Basaloid-squamous carcinoma of the esophagus: report of a case. Surg Today. 2000; 30: 163-7.PMid: 10664341. http://dx.doi.org/10.1007/PL00010064

[16] Ishii A, Chino O, Nishi T, Kise Y, Kenmochi T, Tajima T, et al. Clinicopathological evaluation of basaloid carcinoma of the esophagus on endoscopic diagnosis. Gastroenterol Endosc. 2007; 49: 2953-61 (in Japanese with English abstract).

[17] Noguchi H, Naomoto Y, Haisa M, Yamatsuji T, Shigemitsu K, Shirakawa Y, et al. Two cases of superficial basaloid squamous carcinoma of the esophagus. Dis Esophagus. 2003; 16: 342-5. PMid: 14641302. http://dx.doi.org/10.1111/j.1442-2050.2003.00365.x

[18] Nishimura W, Naomoto Y, Hmaya K, Toda S, Miyagi K, Tanaka N. Basaloid-squamous cell carcinoma of the esophagus: diagnosis based on immunohistochemical analysis. J Gastroenterol Hepatol. 2001; 16: 586-90. PMid: 11350561. http://dx.doi.org/10.1046/j.1440-1746.2001.02424.x

[19] Luna MA, el Nagger A, Parichatikanond P, Weber RS, Batsakis JG. Basaloid squamous carcinoma of the upper aerodigestive tract. Clinicopathologic and DNA flow cytometric analysis. Cancer (Philia). 1990; 66: 537-42. http://dx.doi.org/10.1002/1097-0142(19900801)66:3<537:AID-CNCR2820660322>3.0.CO;2-J

[20] Yoshioka S, Tsujinaka T, Fujitani K, Kawahara K. Prognostic analysis of four cases of basaloid cell carcinoma of the esophageal and 60 records of cases in Japan. Jpn J Gastroenterol Surg. 2004; 37: 290-5 (in Japanese with English abstract). http://dx.doi.org/10.5833/jjgs.37.290 